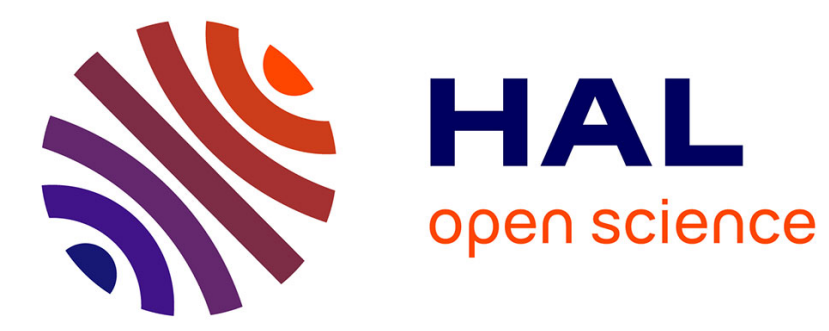

\title{
Development of microfluidic analytical method for on-line gaseous Formaldehyde detection
}

Maud Guglielmino, Alaa Allouch, Christophe A. Serra, Stéphane Le Calvé

\section{To cite this version:}

Maud Guglielmino, Alaa Allouch, Christophe A. Serra, Stéphane Le Calvé. Development of microfluidic analytical method for on-line gaseous Formaldehyde detection. Sensors and Actuators B: Chemical, 2017, 243, pp.963-970. 10.1016/j.snb.2016.11.093 . hal-02273443

\section{HAL Id: hal-02273443 \\ https://hal.science/hal-02273443}

Submitted on 21 Dec 2020

HAL is a multi-disciplinary open access archive for the deposit and dissemination of scientific research documents, whether they are published or not. The documents may come from teaching and research institutions in France or abroad, or from public or private research centers.
L'archive ouverte pluridisciplinaire HAL, est destinée au dépôt et à la diffusion de documents scientifiques de niveau recherche, publiés ou non, émanant des établissements d'enseignement et de recherche français ou étrangers, des laboratoires publics ou privés. 


\title{
DEVELOPMENT OF MICROFLUIDIC ANALYTICAL METHOD FOR ON-LINE GASEOUS FORMALDEHYDE DETECTION
}

\author{
Maud Guglielmino ${ }^{a, b}$, Alaa. Allouch ${ }^{a, b}$, Christophe A. Serra ${ }^{b, c}$, Stéphane Le Calvéa 1 \\ a Institut de Chimie et Procédé pour l'Energie, l'Environnement et la Santé (ICPEES, UMR 7515 CNRS/UdS), \\ groupe physico-chimie de l'atmosphère, 25 rue Becquerel, 67087 Strasbourg Cedex 02, France. \\ b Institut Charles Sadron (ICS) - UPR 22 CNRS, groupe de Chimie Macromoléculaire de Précision (CMP), 23 rue \\ du Loess, 67034 Strasbourg, France.
}

c Université de Strasbourg, Ecole de Chimie, Polymères et Matériaux (ECPM), 25 rue Becquerel, 67087 Strasbourg, France.

\section{Highlights}

- Novel analytical micro-device for quantification of gaseous formaldehyde

- Gaseous Formaldehyde uptake through the establishment of a microfluidic annular flow

- Formaldehyde detection using colorimetric cell using a liquid-core-waveguide

\begin{abstract}
This paper reports on the development of a novel colorimetric analytical method based on microfluidic technologies for the detection of low airborne Formaldehyde concentrations, representative of those found in indoor air, i.e., 10-100 $\mu \mathrm{g} \cdot \mathrm{m}^{-3}$. The new analytical technique operates according to 4 distinct steps: 1) gas sampling, 2) gaseous Formaldehyde uptake into the aqueous solution using an annular gas/liquid flow at room temperature, 3) derivatization reaction with acetylacetone solution at $65^{\circ} \mathrm{C}$ producing 3,5-Diacetyl-1,4-dihydrolutidine (DDL) and 4) colorimetric $\mathrm{DDL}$ detection with a liquid-core-waveguide.

Laboratory experiments were performed to determine the experimental conditions permitting to obtain a stable annular flow, i.e., a liquid flow rate above $5 \mu \mathrm{L} \mathrm{min}^{-1}$ and gas to liquid flow rate ratios greater than 1000. Effects of liquid-core-waveguide of internal diameter and length were also investigated.

Using liquid and gas flow rates of $35 \mu \mathrm{L} \cdot \mathrm{min}^{-1}$ and $35 \mathrm{~mL} \cdot \mathrm{min}^{-1}$ respectively, the resulting uptake yield of gaseous Formaldehyde in aqueous solution was around $90 \%$ and the detection limit of gaseous Formaldehyde was $0.7 \mu \mathrm{g} \cdot \mathrm{m}^{-3}$, which is consistent with the guideline values for indoor air. In addition, the low reagent consumption significantly increases the device autonomy up to 20 days with $1 \mathrm{~L}$ of acetylacetone solution.
\end{abstract}

Keywords: formaldehyde, microfluidics, annular flow, micro-device, indoor air

1 Corresponding author at: Institut de Chimie et Procédé pour l'Energie, I'Environnement et la Santé (ICPEES, UMR 7515 CNRS/UdS) Groupe physico-chimie de l'atmosphère, 25 rue Becquerel 67087 Strasbourg Cedex 0, France Tel. :+33 3688503 68. E-mail address: slecalve@unistra.fr. 


\section{Introduction}

Formaldehyde is a major pollutant of indoor air due to its multiple sources (materials, combustion, painting, etc.) [1]. Several studies [2-4] have shown that indoor Formaldehyde concentrations are 2 to 15 times higher than those measured outdoor and may vary typically between 10 to $100 \mu \mathrm{g} \mathrm{m}^{-3}$. Casset et al. (2006) [5] have shown that Formaldehyde is implicated in allergic diseases, particularly for asthmatic people. As of 2004 Formaldehyde is considered as a carcinogenic compound for humans by the International Agency for Research on Cancer (IARC) [6]. French recommendations aim at limiting Formaldehyde concentrations in public buildings to $30 \mu \mathrm{g} \mathrm{m}^{-3}$ by 2015 and to only $10 \mu \mathrm{g} \mathrm{m}^{-}$ ${ }^{3}$ by 2023 . Therefore, sensitive methods and potentially transportable instruments performing Formaldehyde measurements are highly required.

The conventional method to measure airborne Formaldehyde concentration [7-10] uses a DNPHcartridge sample followed by an off-line laboratory HPLC/UV analysis which is time-consuming and involves a laboratory treatment. In addition, such technique gives average concentrations over intervals of a few tens of minutes to one week, for active and passive samplings, respectively.

Many alternative methods oriented towards real-time and in-field detection, have been developed such as Hantzsch monitor, PTR-MS, infrared diode laser spectroscopy [11-14]. However, most of these methods rely on bulky apparatus and then are not adapted for indoor air monitoring where portability is a key point. Among the developed methods, some of them used reagents which react with Formaldehyde to produce color change which is conveniently used for the detection. Miniature and portable systems have been developed [15-16]. Nevertheless, autonomic, and continuous monitoring over several weeks was often not possible since the reaction on the solid detection element was not reversible. In addition, the resolution of such sensors was usually not as good as needed to detect the very low Formaldehyde concentrations recommended by the state legislature.

As argued by Salthammer et al. in a review on Formaldehyde published in 2010 [1], the method with derivatization to 3,5-Diacetyl-1,4-dihydrolutidine (DDL) in aqueous solution followed by fluorimetric determination is probably the most reliable method of measuring Formaldehyde in indoor air. A similar analytical technique, based on the uptake and concentration of Formaldehyde into an aqueous solution, followed by its specific and complete reaction with acetylacetone in presence of ammonium acetate to form DDL and then the quantification of DDL by fluorescence, has also been developed in our laboratory [17]. Such analyser is very sensitive (LOD $<1 \mu \mathrm{g} \mathrm{m} \mathrm{m}^{-3}$ ) and is considered to be portable and real-time due to its low weight $(8 \mathrm{~kg})$, its response time and temporal resolution (10 minutes). However, its major drawback is the high liquid reagent consumption since it operates at a liquid flow rate of $1.1 \mathrm{~mL} \mathrm{~min}^{-1}$, which is a real limitation since the autonomy is then estimated to be only 15.2 hours with $1 \mathrm{~L}$ of acetylacetone solution. In addition, more miniaturization is always needed for in-field monitoring.

This work aims at developing a new Formaldehyde analytical method which preserves precision, selectivity, sensitivity, and fast analysis in a single miniaturized instrument which will be suitable for field measurement with reagent autonomy sufficient for a one-month monitoring. The contribution of microfluidics in analytical system can allow advantageously achieving all these goals. 


\section{Materials and method}

\subsection{Chemicals}

The reaction between Fluoral-P (or acetylacetone solution) and Formaldehyde producing DDL via a Hantszch reaction illustrated in Figure 1 was first investigated in 1972 (see [18] for more details). Acetylacetone solutions $(0.02 \mathrm{M}$ or $0.01 \mathrm{M})$ were prepared by mixing $0.3 \mathrm{~mL}$ of acetic acid $(100 \%$, Merck), $0.2 \mathrm{~mL}$ of acetylacetone (99\%, Merck), $15.4 \mathrm{~g}$ of ammonium acetate (98\%, Sigma-Aldrich) in 100 or $200 \mathrm{~mL}$ Milli-Q water (18.2 M. $\mathrm{cm}$ at $25^{\circ} \mathrm{C}$, Millipore).

Gaseous Formaldehyde mixtures which concentration was varied from 19.5 to $81.6 \mu \mathrm{g} \mathrm{m}^{-3}\left(6.5 \times 10^{-7}\right.$ to $2.7 \times 10^{-6} \mathrm{M}$ respectively) were prepared by means of a homemade gaseous Formaldehyde source whose development and optimization was reported in a previous work [19]. Briefly, this source generates gaseous Formaldehyde by applying a controlled gas flow $\left(5-20 \mathrm{~mL} \mathrm{~min}^{-1}\right)$ in a microporous tube immersed in a concentrated Formaldehyde solution of $0.0925 \%$ regulated at $10^{\circ} \mathrm{C}$ by a Peltier module. This enriched gaseous Formaldehyde stream is then diluted with a controlled flow (500$2000 \mathrm{~mL} \mathrm{~min}-1$ ) of pure air (>99.999\%) provided by Messer. The concentrated Formaldehyde solution of $0.0925 \%$ was prepared by mixing a commercial Formaldehyde solution (37\% in water, SigmaAldrich) with Milli-Q water $\left(18.2 \mathrm{M} \Omega . \mathrm{cm}\right.$ at $25^{\circ} \mathrm{C}$, Millipore). Finally, the generated gaseous Formaldehyde concentrations were precisely quantified using the conventional sampling method on DNPH cartridges followed by HPLC/UV analysis already described elsewhere [20].

Formaldehyde solutions (5.3 or $53 \mathrm{~g} \mathrm{~L}^{-1}$ ) were prepared by mixing a commercial Formaldehyde solution ( $37 \%$ in water, Sigma-Aldrich) with Milli-Q water $\left(18.2 \mathrm{M} \Omega . \mathrm{cm}\right.$ at $25^{\circ} \mathrm{C}$, Millipore) to lower its concentration down to $1.8 \times 10^{-7}$ or $1.8 \times 10^{-6} \mathrm{M}$ respectively.

\subsection{Setups and experimental conditions}

\subsubsection{Overall setup for detection of gaseous formaldehyde}

The setup used for the quantification of gaseous Formaldehyde is represented in Figure 2. It consisted in four sequential steps: 1) fluid feeding lines, 2) gaseous Formaldehyde uptake into the aqueous solution using an annular gas/liquid flow at room temperature $\left(23^{\circ} \mathrm{C}\right), 3$ ) derivatization reaction with acetylacetone at $65^{\circ} \mathrm{C}$ producing 3,5-Diacetyl-1,4-dihydrolutidine according to Figure 1 and finally 4) DDL detection by colorimetry. The aqueous solution of acetylacetone (0.01 M) was pumped at a flowrate of $35 \mu \mathrm{L} \mathrm{min}{ }^{-1}$ thanks to a peristaltic pump (Ismatec, Reglo Lab) while a gas pump (NMP $850 \mathrm{KTDC}, \mathrm{KNF}$ ) and a gas flow controller (low $\Delta \mathrm{P}$ flow, 0-100 $\mathrm{mL}^{\mathrm{min}} \mathrm{m}^{-1}$, Bronkhorst) ensured the constant flow rate $\left(35 \mathrm{~mL} \mathrm{~min}^{-1}\right)$ of either gaseous Formaldehyde mixture or pure air. The uptake arrangement was composed of a 1/16" peek T-junction (P-728-01, Upchurch) paired with two hydrophilic fused co-axial silica capillaries (Polymicro). The gas mixture flowed through the inner capillary (100 $\mu \mathrm{m}$ ID $\times 150 \mu \mathrm{m}$ OD) while the gas/liquid flow exited the T-junction through a $530 \mu \mathrm{m}$ ID $\times 680 \mu \mathrm{m}$ OD outer capillary. The gas flow rate was thus 3 decades higher that the liquid flow rate which under a specific flow rates ratio gave rise (cf. §3.1) to the formation of an annular flow as illustrated in Figure 2. Due to a very high Henry's constant, $5000 \pm 1200 \mathrm{M} \mathrm{atm}^{-1}$ [21], and a large interface area between gas and liquid phases promoted by the annular flow, the Formaldehyde was transferred from the gas to the liquid phase. The uptake of gaseous Formaldehyde was operated at room temperature $\left(23^{\circ} \mathrm{C}\right)$ although the derivative reaction occurred at $65^{\circ} \mathrm{C}$ to increase the kinetic in order to obtain a full conversion of Formaldehyde to DDL. The gas was removed in flow by means of 
a microporous tube $(\mu \mathrm{PT})$ and the resulting gas-free liquid phase containing the Formaldehyde entered a temperature-controlled oven (Croco-cil, Cluzeau Info Labo) where the derivatization reaction with the acetylacetone was promoted at $65^{\circ} \mathrm{C}$. For the given liquid flow rate of $35 \mu \mathrm{L} \mathrm{min}{ }^{-1}$, the reaction's time of about 3.5 min was controlled through the length of the tubing installed inside the oven. After leaving the oven, the aqueous solution containing the derivatization reaction product (DDL) passed through another microporous tube to remove any bubble that may have been formed during the derivatization procedure including heating process. Finally, the gas-free solution entered the colorimetric cell for DDL detection. This cell was composed of 4 different parts (see Figure 2): i) a liquid-core-waveguide (LCW, BioGeneral), $207 \mu \mathrm{m}$ ID and $44 \mathrm{~cm}$ length, with an inner coating of Teflon ${ }^{\circledR}$ AF 2400 allowing the light to travel through the liquid solution by total reflection. The LCW was wrapped in an aluminum foil to avoid any external parasite light; ii) 2 homemade one-inlet/twooutlet connectors with low dead volume and made of black polymeric material to avoid any parasite light; one port of both T-connector was used to connect the LCW, another port was used for the inlet and outlet (waste) of the DDL solution, finally the last port was used for a SMA adapter to connect in a straight manner the $1500 \mu \mathrm{m}$ optical fibers (IDIL Fibres Optiques) of iii) a Deuterium-halogen light source (DH-2000, Ocean Optics) and iv) a minispectrometer (C10082CAH, Hamamatsu).

\subsubsection{Setup for gas/liquid phase diagram determination}

To determine the flow pattern of the gas/liquid flow inside the outer capillary at room temperature, the setup represented in Figure 3 was used. A syringe pump (Phd 2000, Harvard Apparatus) was used to pump a fresh acetylacetone solution $(0.01 \mathrm{M})$ through a PTFE tubing $(300 \mu \mathrm{m} \mathrm{ID} \times 25 \mathrm{~cm})$. Another syringe pump was used to inject air through a fused silica capillary $(810 \mu \mathrm{m} I \mathrm{D} \times 110 \mathrm{~cm})$. Then the two fluids entered the same aforementioned uptake arrangement detailed in Figure $3.10 \mathrm{~cm}$ downstream to the T-junction, an optical microscope (Eclipse TS 100, Nikon) was placed above the outer capillary to take pictures and record the flow pattern thanks to a CCD camera (PIKE F-032C, Allied Technology) and an imaging software (Hiris, R\&D Vision). Depending on the flow rates of both liquid and gas phases, the flow pattern observed varied from annular flow to slug slow. Thus, to determine the flow pattern inside the outer capillary, the liquid flow rate was varied from 5 to 35 $\mu \mathrm{L} / \mathrm{min}$ while the gas flow rate was varied from 5 to $35 \mathrm{~mL} / \mathrm{min}$. Upon modification of an operating parameter, at least 10 min were elapsed before to record the flow pattern such as the new steady state was reached.

\subsubsection{Setup and experimental conditions to evaluate of the colorimetric detection using liquid Formaldehyde solutions}

The calibration of the colorometric cell was performed with a modified version of the overall setup shown in Figure 4. The Formaldehyde gas line was replaced by a liquid line of an aqueous Formaldehyde solution (0.02 M) pumped thanks to a syringe pump (Phd 2000, Harvard apparatus). A simple peek T junction (P-728-01, Upchurch) ensured the mixing between the two liquid flows before entering in a $0.75 \mathrm{~mm}$ ID $\times 3.2 \mathrm{~m}$ capillary placed inside the same aforementioned temperaturecontrolled oven to promote the derivatization reaction. Step 4, i.e., the colorimetric detection, remained the same. Upon dilution with the acetylacetone solution, the concentration of aqueous Formaldehyde was fixed to $5.3 \mu \mathrm{g} \mathrm{L}^{-1}\left(1.8 \times 10^{-7} \mathrm{M}\right)$. 


\subsubsection{Setup and experimental conditions for the gaseous or aqueous Formaldehyde calibration}

In order to evaluate the uptake yield, both gas and liquid calibrations were performed using the setup detailed in Figure 2. The length of the uptake cell was fixed to $200 \mathrm{~cm}$ whereas the internal diameter and the length of the colorimetric cell detection were 207 microns and $44 \mathrm{~cm}$, respectively. The liquid and gas flow rates were set to $35 \mu \mathrm{L} \mathrm{min}^{-1}$ and $35 \mathrm{~mL} \mathrm{~min}{ }^{-1}$, respectively.

In fact, the experimental apparatus for carrying out liquid phase Formaldehyde calibration is similar to that used for the calibration concentrations of gaseous Formaldehyde. The only two differences are the following: 1) synthetic air free of Formaldehyde replaces the gaseous Formaldehyde mixtures to keep exactly the same residence time in the uptake cell and 2) acetylacetone solution $0.01 \mathrm{M}$ is replaced by a mixture of acetylacetone doped with a known concentration of Formaldehyde prepared as detailed below. First, Formaldehyde concentrations ranging from 20.1 to $316.0 \mu \mathrm{g} \mathrm{L}^{-1}$ $\left(6.7 \times 10^{-7}\right.$ to $\left.1.1 \times 10^{-5} \mathrm{M}\right)$ were prepared in water. They were subsequently diluted by approximately half in a solution of acetylacetone $0.02 \mathrm{M}$ to directly obtain Formaldehyde concentrations ranging from 9.4 to $153.8 \mu \mathrm{g} \mathrm{L}^{-1}$ (from $3.1 \times 10^{-7}$ to $5.1 \times 10^{-6} \mathrm{M}$ ) in a solution of acetylacetone $0.01 \mathrm{M}$.

\section{Results and discussion}

\subsection{Gas/Liquid phase diagram}

To determine the combination of gas and liquid flow rates that provide an annular flow, the acetylacetone/air phase diagram was determined experimentally following the procedure described in section 2.2.2 and illustrated in Figure 3. Results are presented for the $530 \mu \mathrm{m}$ ID outer capillary at room temperature $\left(23^{\circ} \mathrm{C}\right)$ in Figure 5.A. Different patterns were observed, namely slug, slug-annular and annular (Figure 5.B). The slug pattern is to be found in the left part of the phase diagram, i.e., when the gas flow rate is low. When the gas flow rate is increased, an intermediate region appears, and the flow adopts a slug-annular pattern. Finally, when the gas to liquid flow rate ratio is greater than 1,000, a large annular region covers the whole right-hand part of the phase diagram.

In an attempt to compare our results with the literature, data of Figure 6.A were plotted as a function of the gas and liquid superficial velocities and put in regards with the air/water phase diagram obtained in [22] with a $324 \mu \mathrm{m}$ ID capillary at room temperature (Figure 6.B). It is observed that only a small region of our phase diagram (red rectangle) can be compared since most of our data were produced with smaller superficial liquid velocities; moreover, the size of the two capillaries was different. Nevertheless, the agreement is fairly good. Indeed, Sur and Liu [22] diagram shows a transition between slug and slug-annular patterns when the superficial gas and liquid velocities reaches $1.5 \mathrm{~m} \mathrm{~s}^{-1}$ and $2 \times 10^{-3} \mathrm{~ms}^{-1}$, the same for Figure 6.A. Finally, the annular flow is obtained in our case when the superficial gas velocity is higher than $2.5 \mathrm{~m} \mathrm{~s}^{-1}$ which is close to the value of $3 \mathrm{~m} \mathrm{~s}^{-1}$ reported by Sur and Liu in their phase diagram.

To ensure the quantitative transfer of the gaseous Formaldehyde into the liquid phase for further aqueous Formaldehyde derivatization and subsequent DDL quantification in the colorometric cell, the interface area between the gas and liquid phase should be maximized. From Figure 6.B, it can be observed that this is the case only in the annular flow for which the interface area per volume unit of 
gas/liquid mixture is directly proportional to the radius of the gas/liquid interface according to the following equation:

$$
A_{I}=\frac{R_{I}}{4 R_{\text {cap }}^{2}}
$$

where $A_{l}$ is the interface area per unit of volume, $R_{l}$ and $R_{\text {cap }}$ the radii of the interface and capillary (i.e., $265 \mu \mathrm{m}$ ) respectively.

From the analysis of our typical snapshots of the annular flow (Figure 5.B), the interface surface was roughly estimated to be equal to $1.6 \mathrm{~m}^{2} \mathrm{~m}^{-3}$.

\subsection{Evaluation of the colorimetric detection using liquid Formaldehyde solutions}

This experiment was conducted to demonstrate that the use of a liquid-core-waveguide as colorimetric detection cell well checked the Beer-Lambert law and thus the value of the molar extinction coefficient obtained corresponded to that of a molecule of DDL. Four LCW lengths were tested, 10, 20, 40 and $90 \mathrm{~cm}$ for three liquid-core-waveguides of different internal diameters, 207, 400 and $1000 \mu \mathrm{m}$. The concentration of aqueous Formaldehyde was fixed to $5.3 \mu \mathrm{g} \mathrm{L}^{-1}\left(1.8 \times 10^{-7} \mathrm{M}\right)$ in order to determine as accurately as possible, the detection limits used as evaluation parameters in these experiments.

Liquid flow rate was fixed to $104 \mu \mathrm{L} \mathrm{min}{ }^{-1}$ which represents a ten-fold reduction compared to the flow rate used in our previous analytical method [17]. The corresponding LCW residence times varied from 0.03 minutes for a waveguide of $207 \mu \mathrm{m} I D$ and $10 \mathrm{~cm}$ long to 6.79 minutes for a waveguide of $1000 \mu \mathrm{m} \mathrm{ID}$ and $90 \mathrm{~cm}$ long.

According to the Beer-Lambert, absorbance increases linearly with the length of the waveguide whatever its ID as illustrated in Figure 7. From the obtained slope, the molar extinction coefficient of $\operatorname{DDL}(\varepsilon)$ can be extracted. This value is equal to $\varepsilon=7320 \pm 610 \mathrm{M}^{-1} \mathrm{~cm}^{-1}$ at $415 \mathrm{~nm}$, the error bars correspond to $2 \sigma$. This result is in very good agreement with the value reported in the literature for $\mathrm{DDL}, \varepsilon=7500 \mathrm{M}^{-1} \mathrm{~cm}^{-1}[11]$.

The detection limits determined for both colorimetric cells (i.e., LCW ID of 207 and 1000 microns) are summarized in Table 1 for the different lengths of the waveguide and vary between 0.3 and $1.9 \mu \mathrm{g} \mathrm{L}^{-1}$ using a signal noise ratio of 3 . Even if the detection limit is slightly lower with the LCW of $1000 \mu \mathrm{m} I D$, the following experiments were conducted with the LCW of $207 \mu \mathrm{m}$ because of the solution residence time which is significantly shorter, the LCW length being fixed to $44 \mathrm{~cm}$.

\subsection{Gaseous Formaldehyde calibration}

Regarding the above results obtained on the Gas/Liquid phase diagram and the colorimetric detection using LCW, the microfluidic analytical method shown in Figure 2 was calibrated using 1) a liquid and gas flow rates of $35 \mu \mathrm{L} \mathrm{min}{ }^{-1}$ and $35 \mathrm{~mL} \mathrm{~min}^{-1}$ respectively and a LCW of $207 \mu \mathrm{m}$ ID and 44 $\mathrm{cm}$ length in order to obtain 1) an annular flow and 2) to reduce significantly the time response.

The calibration was performed for gaseous Formaldehyde concentrations varying from 19.5 to 81.6 $\mu \mathrm{g} \mathrm{m}^{-3}\left(6.5 \times 10^{-7}\right.$ to $\left.2.7 \times 10^{-6} \mathrm{M}\right)$, this range corresponds to Formaldehyde concentrations typically found in indoor air. The absorbance signals obtained for these concentrations are shown in Figure 8. They are centered on a wavelength of $415 \mathrm{~nm}$ corresponding to the maximum absorbance of the DDL 
in accordance with the literature [11,23]. The signals obtained for high concentrations are much noisy at the optimum absorption wavelength, this is partly due to the high absorbance values, close to 1 .

As shown in Figure 9, the absorbance signal increases linearly $\left(R^{2}=0.999\right)$ when the gas phase concentration increases. Considering an absorbance noise of $2.7 \times 10^{-3}$, the detection limit of the analytical device in this configuration (gas uptake and colorimetric detection) is in the order of $0.7 \mu \mathrm{g}$ $\mathrm{m}^{-3}$ for a signal noise ratio equal to 3 . The limit quantification was estimated to $2.3 \mu \mathrm{g} \mathrm{m}^{-3}$ for a signal to noise ratio equal to 10 .

\subsection{Uptake yield}

Ideally, the uptake efficiency of gaseous Formaldehyde must be reproducible and equal to $100 \%$, particularly if the Beer-Lambert law is used to calculate the concentration of Formaldehyde in the solution and therefore to deduce the concentration of gaseous formaldehyde.

For a DDL molecule, the molar absorption coefficient $\varepsilon$ is equal to $7500 \mathrm{M}^{-1} \mathrm{~cm}^{-1}$ from the literature [11]. This value agrees well with our experimental value of $7320 \pm 610 \mathrm{M}^{-1} \mathrm{~cm}^{-1}$ (see section 3.2) obtained with our absorption cell composed of a liquid-core-waveguide. Knowing the absorbance measured experimentally, the molar extinction coefficient and the optical path length (equivalent to the length of the waveguide), it is possible to determine the experimental concentration of the DDL by applying the Beer-Lambert law:

$$
A=\text { slc }
$$

where $A$ is the absorbance, $\varepsilon$ the molar absorption coefficient, I the optical path length and $c$ the compound concentration.

The number of Formaldehyde moles experimentally trapped ( $\mathrm{n}_{\text {нсно ехр }}$ ) into the solution can be calculated from the measured absorbance. If the uptake of the gaseous Formaldehyde is total, the number of gaseous Formaldehyde moles is quantitatively transferred into the aqueous solution, which allows to determine the number of Formaldehyde moles theoretically trapped $\left(\mathrm{n}_{\mathrm{HCHO}} \mathrm{th}\right)$ into the solution. The uptake yield is then the ratio between the number of Formaldehyde moles trapped experimentally and the theoretical value considering an uptake yield of $100 \%$.

$$
\text { Yield }(\%)=\frac{n_{\text {HCHO exp }}}{n_{\text {HCHO th }}} \times 100
$$

In our series of experiments, the uptake yield for gaseous Formaldehyde concentrations varying from 19.5 to $81.6 \mu \mathrm{g} \mathrm{m}^{-3}\left(6.5 \times 10^{-7}\right.$ to $\left.2.7 \times 10^{-6} \mathrm{M}\right)$ was $90 \pm 2 \%$ whatever the concentrations as illustrated in Table 2. This uptake yield is then quite high and ensures almost the quantitative Formaldehyde transfer from gas to the aqueous solution.

\section{Conclusions}

The acetylacetone solution/Formaldehyde gas phase diagram was determined for a $530 \mu \mathrm{m}$ ID capillary by varying the liquid and gas flow rate in the range 5 to $35 \mu \mathrm{L} \mathrm{min}{ }^{-1}$ and 5 to $35 \mathrm{~mL} \mathrm{~min} \mathrm{~m}^{-1}$ respectively. The annular flow, the sole flow pattern among the three we observed which maximizes the surface area between gas and liquid required for a quantitative transfer of gaseous 
Formaldehyde into the liquid phase, was found to occupy a large region of the phase diagram for liquid flow rate above $5 \mathrm{~min}^{-1}$ and gas to liquid flow rate ratios greater than 1000 .

Our experimental work performed under controlled gaseous Formaldehyde concentrations showed that the device based on a microfluidic annular two-phase flow to achieve the uptake of gaseous Formaldehyde had a linear response permitting to quantify typical indoor air concentrations of Formaldehyde in the range $0-100 \mu \mathrm{g} \mathrm{m}^{-3}$. This new device is characterized by its excellent analytical performances such as the observed high uptake yield of $90 \%$ as well as the relatively low detection and quantification limits, i.e., 0.7 and $2.3 \mu \mathrm{g} \mathrm{m}^{-3}$ respectively.

With $1 \mathrm{~L}$ of acetylacetone solution and a liquid flow rate of $35 \mu \mathrm{L} \mathrm{min}{ }^{-1}$, the reagent autonomy increases significantly up to 19.8 days for a continuous Formaldehyde monitoring against only 15.2 hours for the previous analytical technique.

\section{Acknowledgement}

This work is supported by ADEME and Region Alsace, REALISE, the program PRIMEQUAL and ANR (ANR-11-ECOT-0013). 


\section{References}

1. T. Salthammer, S. Mentese and R. Marutzky - Formaldehyde in the Indoor Environment, Chem. Rev., 110 (2010) 2536-2572.

2. B. Wang, S.C. Lee and K.F. Ho - Characteristics of carbonyls: Concentrations and source strengths for indoor and outdoor residential microenvironments in China, Atmos. Environ., 41 (2007) 2851-2861.

3. N.L. Gilbert, Guay M. and D. et al Gauvin - Air change rate and concentration of formaldehyde in residential indoor air, Atmos. Environ., 42 (2008) 1336-1345.

4. X. Wang, H. Wang and S. Wang - Ambient formaldehyde and its contributing factor to ozone and $\mathrm{OH}$ radicals in a rural area, Atmos. Environ., 44 (2010) 2074-2078.

5. A. Casset, C. Marchand, A. Purohit, S. Le Calvé, C. Donnay, P. Meyer, G. Pauli and F. de Blay Low exposo miteure to inhaled formaldehyde: effect on allergen bronchial response in asthmatics sensitized to mite, J. of Allergy and Clinical Immunology, S23 (2006) 117.

6. IARC - Overall evaluation of carcinogenicity to humans, formaldehyde, International Agency for Research on Cancer, (2004) [50-00-0].

7. X. Zhou and K. Mopper - Apparent partition coefficients of 15 carbonyl compounds between air and seawater and between air and freshwater; Implications for air-sea exchange, Environ. Sci. Technol., 24 (1990) 1864-1869.

8. K. Müller - Determination of aldehydes and ketones in the atmosphere : A comparative long time study at an urban and a rural site in Eastern germany, Chemosphere 35 (1997) 20932106.

9. R.M. Cerón, J.G. Cerón and M. Muriel - Diurnal and seasonal trends in carbonyl levels in a semi-urban coastal site in the Gulf of Campeche, Mexico, Atmos. Environ. , 41 (2007) 63-71.

10. T. Wangchuk, C. He, M.R. Dudzinska and L. Morawska - Seasonal variations of outdoor air pollution and factors driving them in the school environment in rural Bhutan, Atmos. Environ., 113 (2015) 151-158.

11. T. Salthammer - Photophysical properties of 3,5-diacetyl-1,4_dihydrolutidine in solution: application to the analysis of formaldehyde, J. Photochem. Photobiol. A: Chem., 74 (1993) 195-201.

12. B.T. Jobson and J.K. Mc Coskey - Sample drying to improve HCHO measurements by PTR-MS instruments: laboratory and field measurements, Atmos. Chem. Phys. Discuss., 9 (2009) 19845-19877.

13. A. Vlasenko, A.M. Macdonald, S. J. Sjostedt and J. P. D. Abbatt - Formaldehyde measurements by Proton transfer reaction - Mass Spectrometry (PTR-MS): correction for humidity effects, Atmos. Meas. Tech., 3 (2010) 1055-1062.

14. B. Hanoune, T. Le Bris, L. Allou, C. Marchand and S. Le Calvé - Formaldehyde measurements in libraries: Comparison between infrared diode laser spectroscopy and a DNPH-derivatization method, Atmos. Environ., 40 (2006) 5768-5775.

15. K. Toda, W. Tokunaga and Y. et al. Gushiken - Mobile monitoring along a street canyon and stationary forest air monitoring of formaldehyde by means of a micro-gas analysis system, Journal of Environmental Monitoring, 14 (2012) 1462-1472.

16. A. Allouch, M. Guglielmino, P. Bernhardt, C. Serra and S. Le Calvé - Transportable, fast and high sensitive near real-time analyzers: formaldehyde detection, Sensors and Actuators B: Chemical, 181 (2013 and references therein) 551-558.

17. S. Le Calvé, W. Zheng, J.L. Ponche and P. Bernhardt, Device and method for determining the concentration of a compound in an aqueous or gaseous phase. 2012: France. p. 12-16.

18. U. Eisner and J. Kuthan - Chemistry of dihydropyridines, Chemical Reviews, 72 (1972) 1-42.

19. W. Zheng, Développement d'un analyseur rapide et transportable du formaldéhyde dans l'air, in PhD thesis in Chemistry 2010, University of Strasbourg.

20. C. Marchand, B. Bulliot, S. Le Calvé and Ph. Mirabel - Aldehyde Measurements in indoor environment in Strasbourg (France), Atmos. Environ., 40 (2006) 1336-1345. 
21. L. Allou, L. El Maimouni and S. Le Calvé - Henry's Law Constant measurements for formaldehyde and benzaldehyde as a function of temperature and water composition, Atmos. Environ., 45 (2011) 2991-2998.

22. A. Sur and D. Liu - Adiabatic air-water two-phase flow in circular microchannels, Int. J. Therm. Sci., 53 (2012) 18-34.

23. T. Nash - The colorimetric estimation of formaldehyde by means of the Hantzsch reaction, Biochem. J., 55 (1953) 416-423. 